\title{
Neurorestorative interventions involving bioelectronic implants after spinal cord injury
}

\author{
Newton Cho ${ }^{1,2}$, Jordan W. Squair ${ }^{1,3,4}$, Jocelyne Bloch ${ }^{5,6}$ and Grégoire Courtine ${ }^{1,5,6^{*}}$ (D)
}

\begin{abstract}
In the absence of approved treatments to repair damage to the central nervous system, the role of neurosurgeons after spinal cord injury (SCl) often remains confined to spinal cord decompression and vertebral fracture stabilization. However, recent advances in bioelectronic medicine are changing this landscape. Multiple neuromodulation therapies that target circuits located in the brain, midbrain, or spinal cord have been able to improve motor and autonomic functions. The spectrum of implantable brain-computer interface technologies is also expanding at a fast pace, and all these neurotechnologies are being progressively embedded within rehabilitation programs in order to augment plasticity of spared circuits and residual projections with training. Here, we summarize the impending arrival of bioelectronic medicine in the field of SCl. We also discuss the new role of functional neurosurgeons in neurorestorative interventional medicine, a new discipline at the intersection of neurosurgery, neuro-engineering, and neurorehabilitation.
\end{abstract}

Keywords: Spinal cord injury, Neuromodulation, Brain-computer interface, Electrical stimulation, Neurosurgery

\section{Background}

A century of medical research and clinical practice has transformed the management of patients with spinal cord injury (SCI). The standards of good clinical practice for a traumatic SCI consist of stabilizing spine fractures, decompressing the spinal cord, and maintaining optimal hemodynamics to avoid hypotension and secondary spinal cord damage. As soon as possible, the patient is transferred to a specialized SCI center where expert clinical teams deploy intensive rehabilitation programs and educate patients in the management of their bladder, bowel, and general body condition.

These surgical procedures, supportive measures, and rehabilitation programs have ameliorated neurological outcomes and decreased morbidity in patients with SCI (Fehlings et al. 2017). However, there is currently still no clinical trial that has reported robust efficacy of a spinal cord repair strategy for improving functional recovery after SCI. Due to the limited ability of the spinal cord for

\footnotetext{
* Correspondence: gregoire.courtine@epfl.ch

'École polytechnique fédérale de Lausanne (EPFL), Campus Biotech, Center

for Neuroprosthetics and Brain Mind Institute, 1202 Genève, Switzerland

${ }^{5}$ Department of Neurosurgery, University Hospital of Lausanne (CHUV),

Lausanne, Switzerland

Full list of author information is available at the end of the article
}

repair, many neurological deficits remain permanent, with devastating health consequences and substantial financial and social burdens for society. Until now, functional neurosurgeons are remotely involved in SCI medicine and their role remains confined to the management of spasticity or neuropathic pain with spinal cord stimulation.

Here, we summarize a series of preclinical and clinical advances in the development of neuromodulation therapies, brain-computer interfaces, and neurotechnologysupported neurorehabilitation programs that herald a new role of functional neurosurgeons in the restoration of neurological functions after SCI (Table 1).

\section{The era of restorative neurosurgery}

The brain broadcasts movement-related commands through parallel neuronal pathways that cascade from the cortex and brainstem to executive centers residing in the spinal cord (Arber and Costa 2018). An SCI scatters this exquisitely-organized communication system, which results in severe motor deficits and alters critical physiological functions. However, most SCIs spare bridges of intact neural tissue that contain fibers still connected to executive centers located below the injury. For unclear reasons, these anatomically intact neural projections 


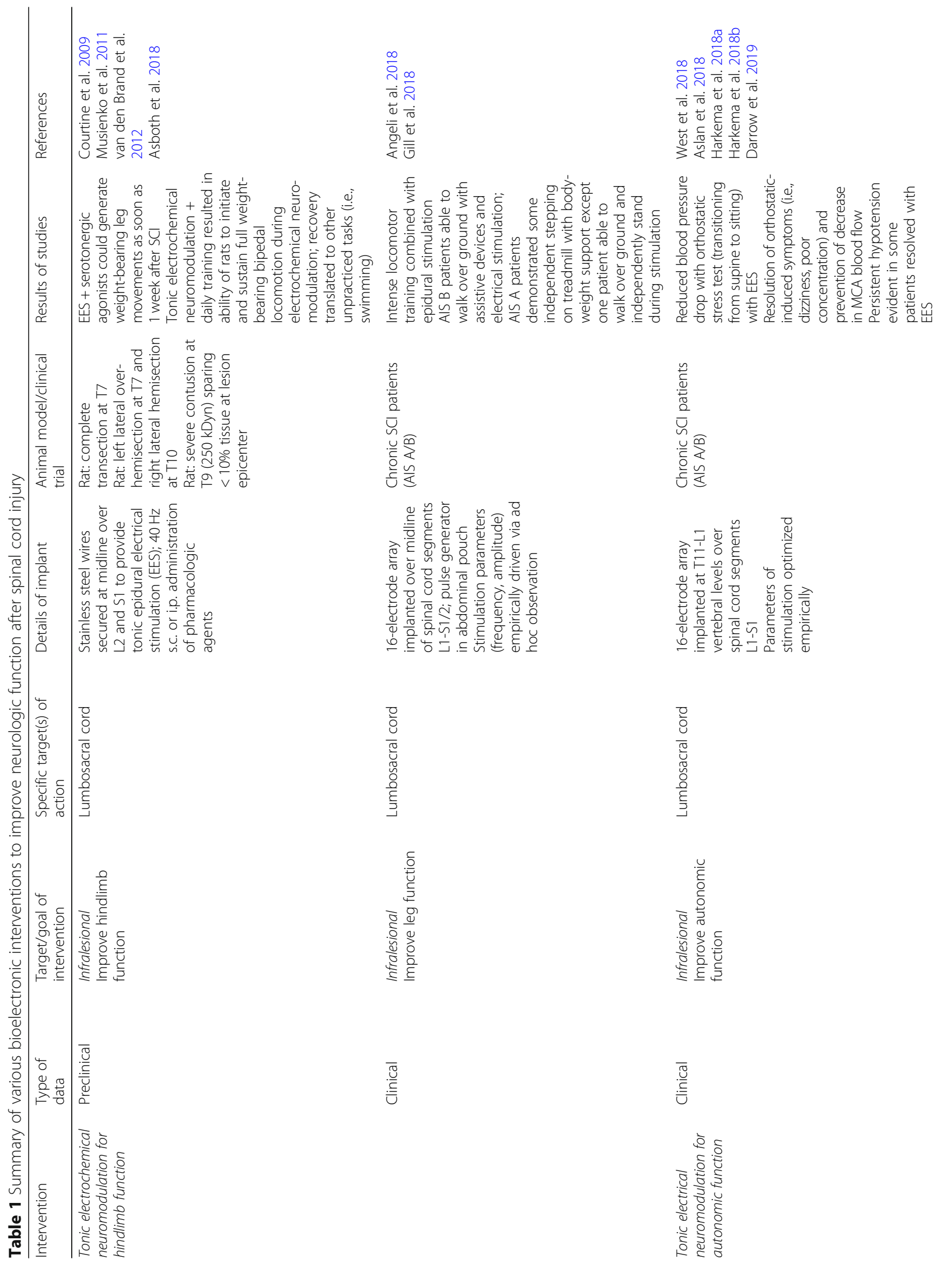




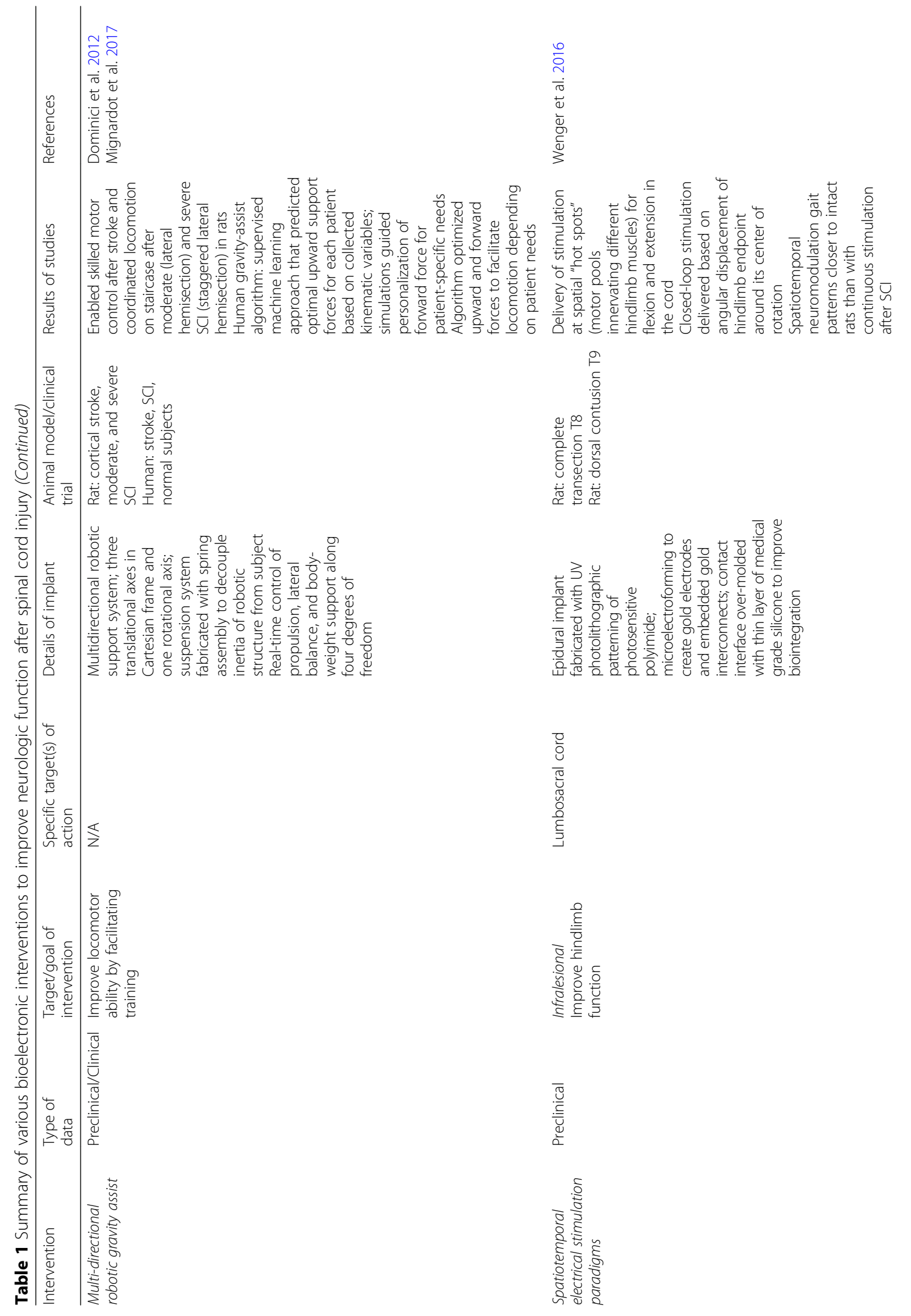




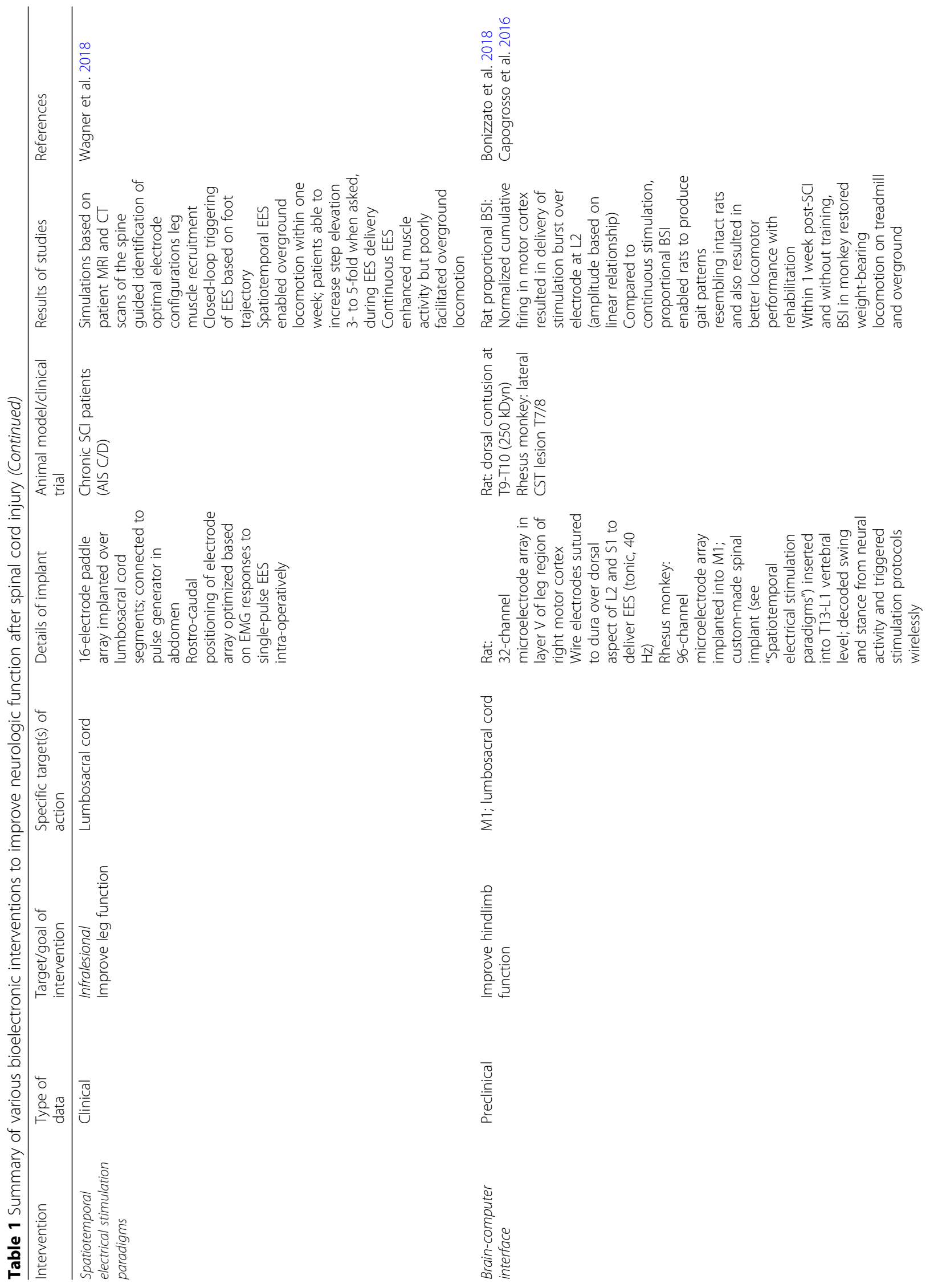




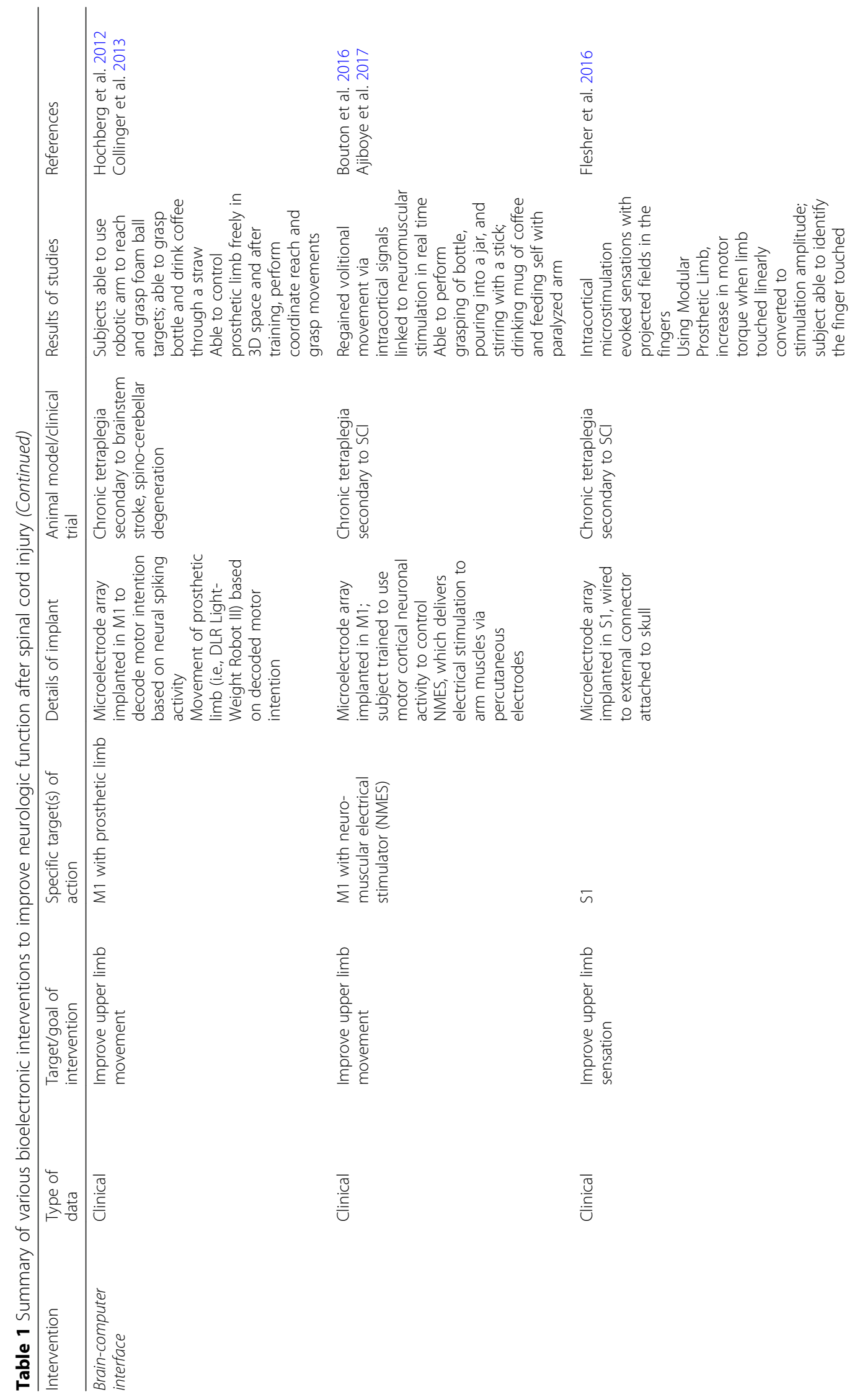




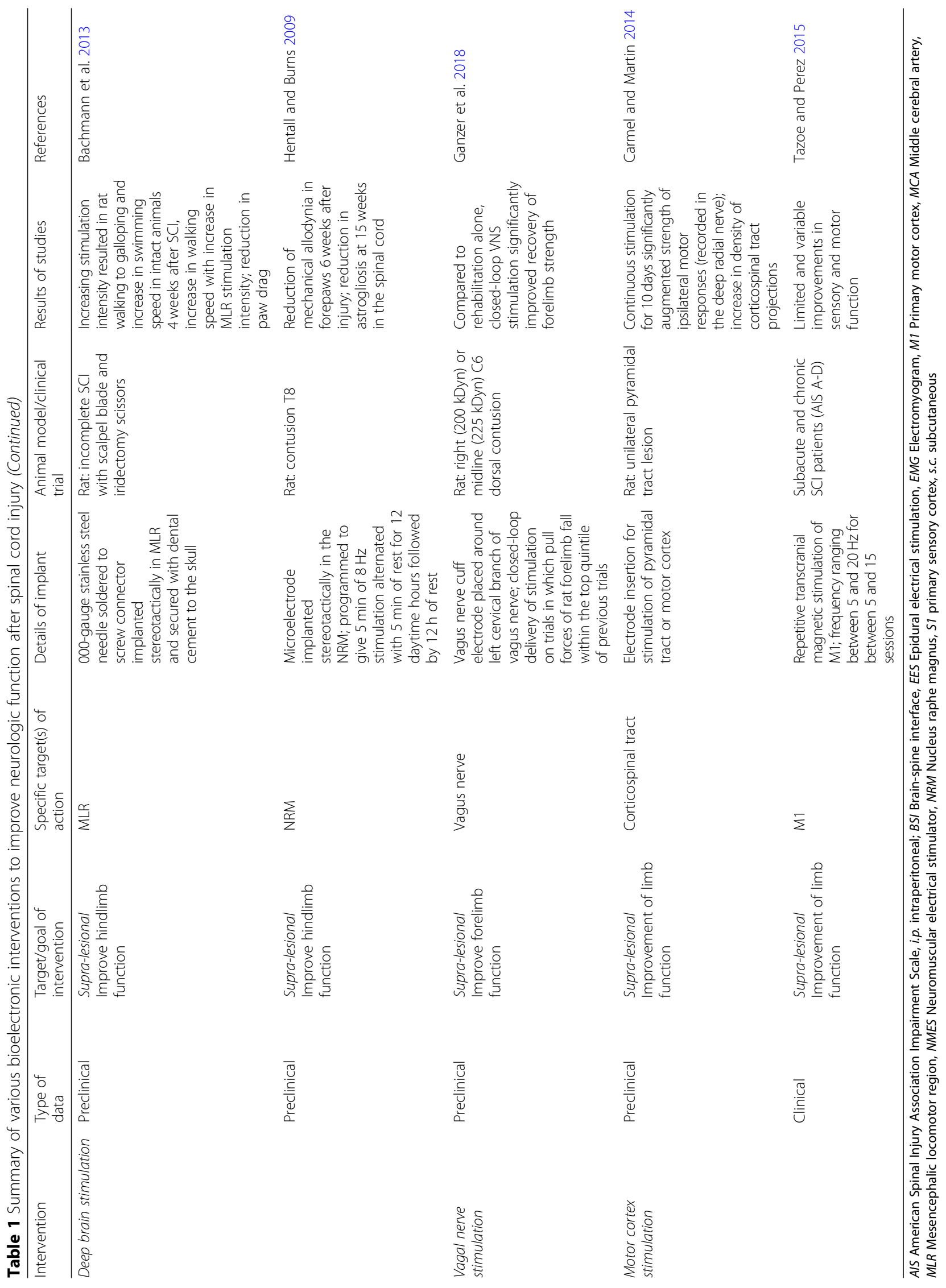


remain functionally silent. Moreover, the vast majority of circuits involved in producing movements and regulating physiological functions are distant from the spinal cord damage. Consequently, the anatomical integrity of these circuits is not compromised. This understanding has triggered the development of engineering interventions that tap into residual projections and spared circuits to enable the control of movements, regulate physiological functions, and improve neurological recovery.

These interventions all have in common the surgical implantation of bioelectronic devices connected to electrode arrays in order to record from neural ensembles or deliver electrical stimulation. Bioelectronic treatments focusing on the delivery of electrical stimulation are a type of neuromodulatory therapy. These stimulation-based neuromodulation therapies target circuits that can be located below the injury (infralesional, Fig. 1) or at different levels above the injury (supralesional, Fig. 2). The simplest approach involves the delivery of continuous stimulation over broad regions of the brain, midbrain and spinal cord, or even to peripheral nerves. However, the identification of the mechanisms through which electrical stimulation paradigms modulate circuits have led to more effective stimulation protocols that are modulated in the temporal and/ or spatial domains. The conception of neuromodulation therapies that are directly controlled via brain signals is also emerging quickly.
All these treatments involve the contribution of a functional neurosurgeon who not only needs to implant one or several bioelectronic devices, but also must interact effectively with multidisciplinary teams of engineers, neurologists, and physical therapists in order to deploy these treatments. Below, we summarize the scientific basis and technological framework of each of these bioelectronic treatments, and envision the steps forward to turn current proofs of concepts into widely available medical treatments for SCI.

\section{Targeting circuits below the $\mathrm{SCl}$ : infralesional neuromodulation therapies}

Reactivating spinal circuits involved in producing movement

The specialized features of locomotor-related descending commands originating from the brainstem remain vividly debated and studied. However, their functional contribution can be (over) simplified into two main functions: provide monoaminergic modulation and glutamatergic excitation. The interruption of descending pathways from the brainstem thus deprive spinal circuits from these essential sources of modulation and excitation. While executive centers residing in the spinal cord are intact, they fail to produce leg movements. This understanding triggered the development of neuromodulation therapies that seek to replace these missing sources of modulation and excitation to reactivate spinal circuits, and thus enable motor control.

Neuromodulation of circuits below the injury

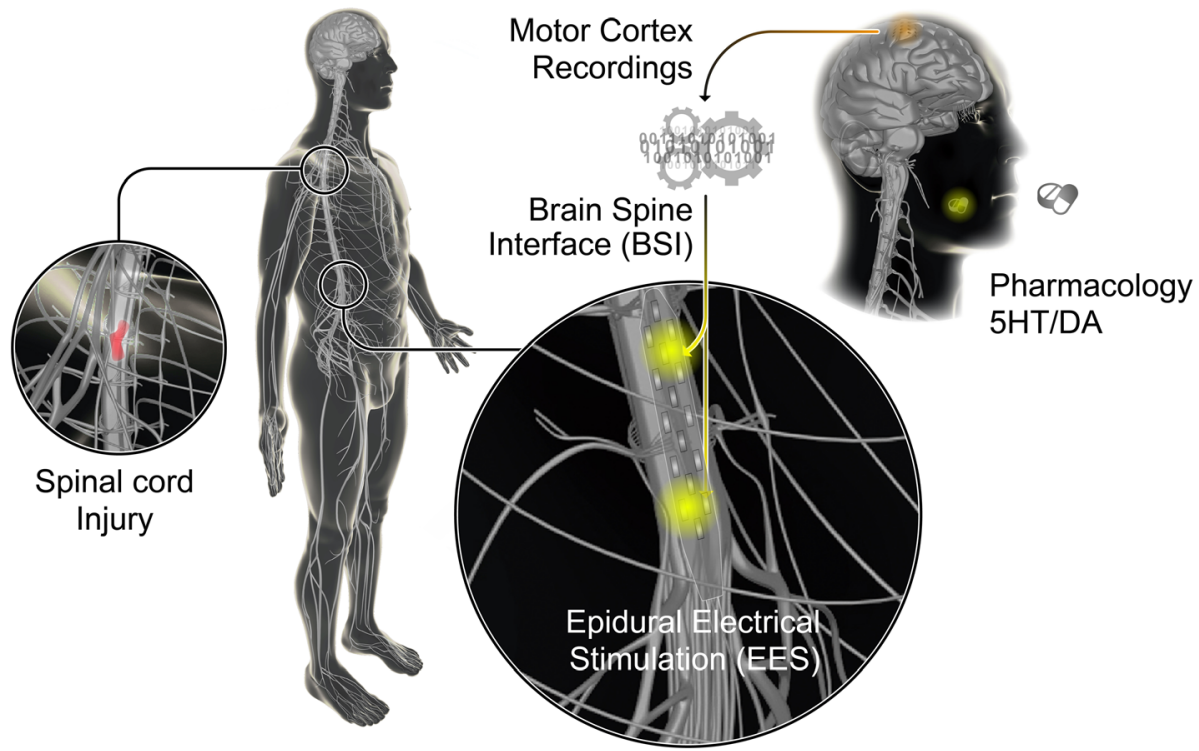

Fig. 1 Neuromodulation strategies to engage circuits below the lesion after SCI. The reactivation or modulation of spinal circuits for locomotion has been demonstrated with the use of epidural electrical stimulation (EES) combined with the oral or intrathecal administration of serotonergic and dopaminergic agonists. EES can also be used to optimize autonomic function post-SCI (i.e., blood pressure management). Brain-spine interfaces (BSIs) also provide an alternative strategy for locomotion through bypassing the injury 

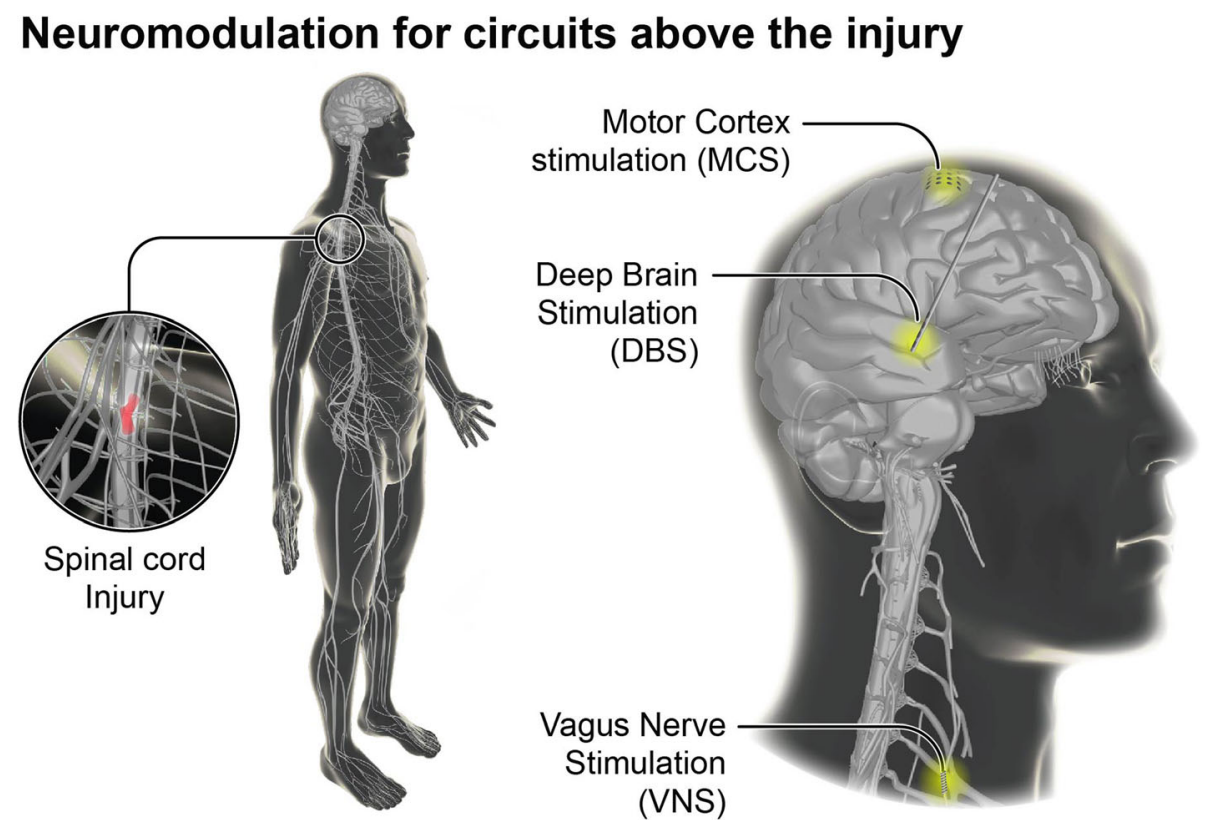

Fig. 2 Neuromodulation strategies to engage circuits above the lesion after SCI. Neuromodulation therapies have been delivered to the mesencephalic locomotor region (MLR) using deep brain stimulation (DBS) in order to facilitate locomotion. Motor cortex stimulation (MCS) has been applied for extensive periods of time daily to promote the growth and sprouting of corticospinal tract fibers. Finally, vagus nerve stimulation (VNS) has been applied to augment motor learning and plasticity during motor rehabilitation

Preclinical research in mammal models showed that pharmacological agents and electrical spinal cord stimulation were highly effective to reactivate executive spinal circuits involved in leg motor control. The pharmacological agents can target a broad range of serotonin, dopamine and noradrenaline receptor subtypes that each modulate specific features of movement such as weight bearing capacities or inter-limb coordination (Musienko et al. 2011; Rossignol et al. 2001). The most effective pharmacological interventions targeted $5 \mathrm{HT}_{1 \mathrm{~A}}, 5 \mathrm{HT}_{2 \mathrm{~A} / \mathrm{C}}$ and $5 \mathrm{HT}_{7}$ receptors subtypes-for example with Quipazine and 8-OHDPAT (Courtine et al. 2009). Direct spinal cord stimulation has been achieved with invasive and noninvasive neurotechnologies that include intraspinal stimulation/epidural electrical stimulation and transcutaneous electrical stimulation/magnetic stimulation, respectively (Gerasimenko et al. 2015; Wenger et al. 2016; Grahn et al. 2017; Angeli et al. 2015; Herman et al. 2002; van den Brand et al. 2012; Danner et al. 2015; Minev et al. 2015; Holinski et al. 2016; Zimmermann et al. 2011; Kasten et al. 2013; Angeli et al. 2014; Lu et al. 2016). Thus far, epidural electrical stimulation (EES) applied over the dorsal aspect of the spinal cord has been the most promising paradigm to engage lumbosacral circuits. Even in the complete absence of supraspinal input, the administration of serotonergic agonists and continuous EES enabled the immediate production of complex motor behaviors. Mice, rats, and cats with complete mid-thoracic transection were thus able to stand and walk over a broad range of speeds and directions while supporting their body weight (Courtine et al. 2009; Dominici et al. 2012). Under these conditions, task-specific sensory information arising from the legs becomes the source of modulation that governs the production of movement (Fong et al. 2009).

When the interruption of descending pathways is complete, these movements remain involuntary. However, studies in incomplete rodent models of SCI showed that a small percentage of spared fibers is sufficient to reestablish voluntary control of executive centers in the lumbosacral spinal cord. For example, after a severe contusion SCI that spares less than $10 \%$ of white matter tracts, the delivery of pharmacological and electrical neuromodulation therapies instantly enabled graded cortical control over the degree of leg extension during locomotion (Asboth et al. 2018). Since these contusions abolish all corticospinal tract synaptic projections below the injury, the cortical command cannot be conveyed directly to the lumbosacral spinal cord. Indeed, optogenetic and chemogenetic manipulations demonstrated that glutamatergic projection neurons located in the ventral gigantocellular nucleus (reticular formation) relay the cortical command to the spinal cord (Asboth et al. 2018). The ubiquitous location of reticulospinal fibers in the white matter ensures that a subset of these projections are spared, regardless of the inherently variable location of spinal cord damage. It is important to understand that in the absence of spinal cord neuromodulation therapies, these spared descending fibers are 
functionally silent. They fail to elicit any detectable muscle contraction. Neuromodulation therapies thus amplify the residual commands from the brain. In these conditions, executive centers in the spinal cord process supraspinal and sensory information in order to integrate volition into the execution of movements that are continuously adapted to the requirements of the performed tasks.

Studies in preclinical models of SCI evolved in parallel to multiple case studies conducted in humans with incomplete or complete SCI. To modulate the spinal cord electrically, scientists used single leads or paddle electrode arrays implanted over the lumbar spinal cord that they interfaced with implantable pulse generators commonly used in pain treatments. Studies from multiple independent laboratories thus showed that the delivery of continuous electrical stimulation (tonic) over the lumbar spinal cord immediately reestablished intentional control over the activity of previously paralyzed leg muscles, even more than a decade after the occurrence of the SCI. Continuous EES also restored full weight-bearing standing and facilitated stepping (Angeli et al. 2018; Gill et al. 2018). It was also shown that monoaminergic agonists could amplify the facilitation of movement mediated by electrical spinal cord stimulation (Gerasimenko et al. 2015) . These clinical studies confirmed the validity of the concepts established in preclinical models, which triggered a surge of interest for the development of neurotechnologies that are optimized for motor-related applications.

The combination of finite element modeling (FEM) of electrical spinal cord stimulation with anatomically realistic models of the main afferent and efferent circuits located in the spinal cord revealed that the electrical fields elicited by EES do not penetrate the spinal cord (Capogrosso et al. 2013; Rattay et al. 2000). Consequently, EES does not modulate motor neurons directly. The electrical current flows around the spinal cord within the cerebrospinal fluid (CSF) where it activates the neural structures with the lowest impedance. The large-diameter proprioceptive afferent fibers are the least resistive neural elements in this region. Therefore, EES depolarizes proprioceptive afferent fibers at their entrance in the spinal cord, where they exit the posterior roots. The extensive branches of proprioceptive fibers in the spinal segments rostral and caudal to their entrance lead to a broad increase in the excitability of spinal circuits (Edgerton et al. 2008; Gerasimenko et al. 2007; Ichiyama et al. 2008; Musienko et al. 2012). In addition, each afferent volley leads to the trans-synaptic activation of motor neurons through the recruitment of proprioceptive feedback circuits (Dy et al. 2005; Lavrov et al. 2008a; Lavrov et al. 2008b). Concretely, each pulse of EES gives rise to monosynaptic and polysynaptic motor responses, the succession of which contributes to elaborating the activity of leg muscles (Wenger et al. 2016; Capogrosso et al. 2013;
Capogrosso et al. 2018; Moraud et al. 2016). EES frequency determines how frequently proprioceptive feedback circuits are recruited, and thus how much activity is elicited in leg muscles (Wenger et al. 2014).

This understanding led to a paradigm shift in the design of stimulation protocols (Capogrosso et al. 2018). The reasoning was the following: if motor neurons are engaged indirectly through the recruitment of proprioceptive afferents located in the posterior roots, then targeting individual posterior roots would provide access to the motor neuron pools located in the spinal segment innervated by each root. These predictions have been verified consistently in rodent (Wenger et al. 2016) and nonhuman primate models (Capogrosso et al. 2016), and more recently in humans (Wagner et al. 2018). This spatial selectivity suggested that the delivery of spatiallyselective trains of EES with a timing reproducing taskdependent activation of motor neuron pools would result in a more robust and more physiological activation of the spinal cord during movement execution (Fig. 3). This spatiotemporal neuromodulation strategy restored full weight bearing locomotion in rats with complete SCI, which was not possible with continuous EES (Wenger et al. 2016). Since the recruitment of motor neuron pools with EES was restricted to the phase during which they were active, the amplitude and frequency of EES could be manipulated over a broad range of values. This large parameter space allowed the control of leg muscle activity with high precision. A simple tuning of EES amplitude or frequency enabled a precise adjustment of the extent of flexion and extension movements. For example, real-time control of EES parameters allowed rats with complete SCI to climb up staircases of various heights and lengths with fluidity (Wenger et al. 2016; Wenger et al. 2014).

Translation of this spatiotemporal stimulation strategy in humans required upgrading an implantable pulse generator commonly used for deep brain stimulation therapies with wireless modules that enabled real-time control over the location and timing of multiple concomitant EES bursts (Fig. 3). The pulse generator was connected to a paddle electrode array used for pain therapies. Since the configuration of the electrodes was not tailored for motor-related applications, the surgical positioning of the array was critical. Before surgery, a personalized computational model of the lumbosacral spinal cord was elaborated from a high-resolution MRI scan for each patient. Computer simulations guided the neurosurgeon in the positioning of the array, which was fine-tuned based on electrophysiological recordings (Wagner et al. 2018).

The delivery of EES bursts matching the spatial and temporal dynamics of natural motor neuron activation led to an immediate recovery of locomotion. Within 5 days, all tested individuals who had sustained a severe SCI 


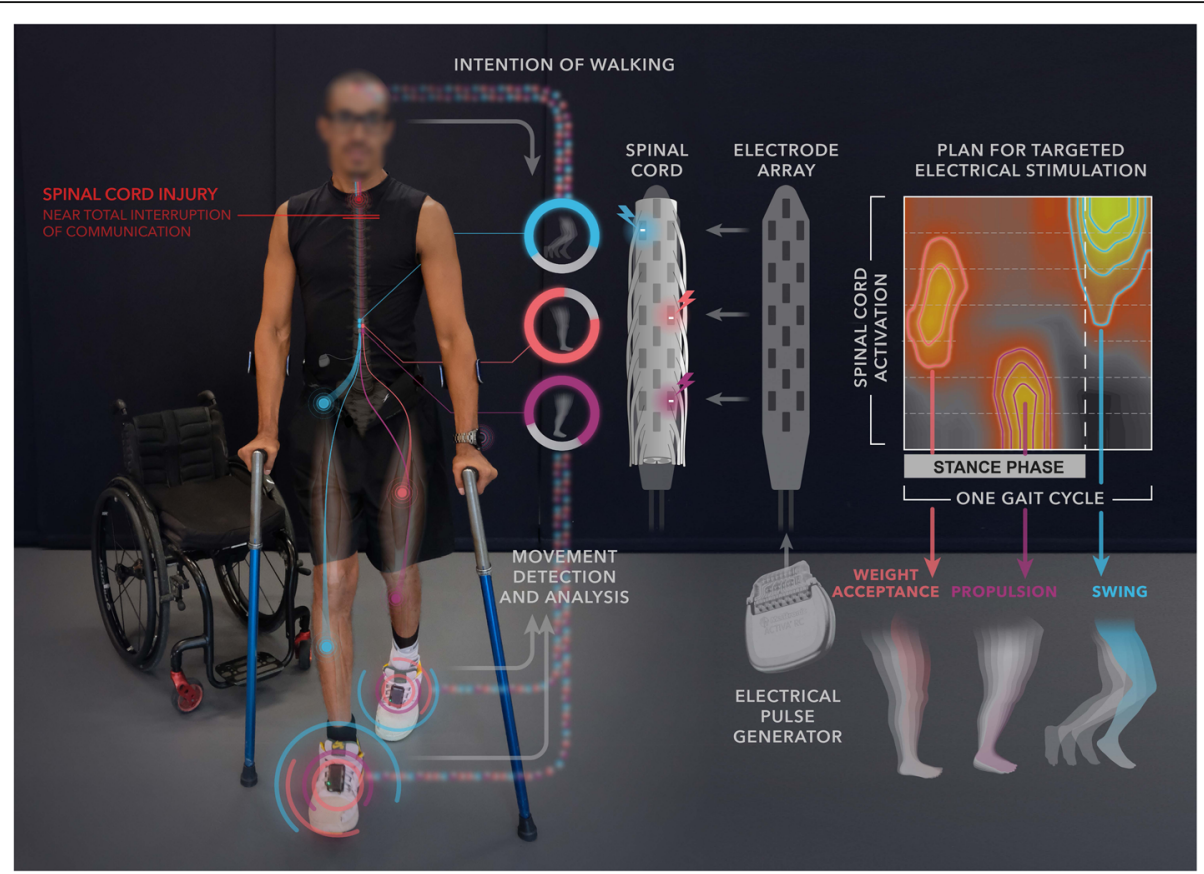

Fig. 3 Spatiotemporal EES reproduces the natural activation of the spinal cord. Delivery of EES bursts matching the spatial and temporal dynamics of natural motor neuron activation immediately enables locomotion after SCl. Decoding algorithms detect foot movements in order to adjust the location and timing of the spatiotemporal stimulation sequences to the current needs of the patient. The spinal cord activation map is reconstructed based on the projection of electromyographic recordings onto the theoretical location of motor neurons in the spinal cord

several years prior to the surgical intervention were able to produce weight-bearing, independent stepping movements on a treadmill and overground (Fig. 4). Instead, continuous EES was poorly effective in these participants due to the cancellation of proprioceptive information that occurs during continuous EES in humans (Formento et al. 2018). Spatiotemporal stimulation paradigms mitigate the cancellation of proprioceptive information, since afferent populations are recruited transiently and in phase with the movement they encode.

After 1 month of tuning and habituation to the stimulation, individuals who were not able to take independent steps without stimulation exhibited coordinated locomotion for duration as long as 1 hour, covering up to 1 kilometer in 1 hour without external assistance. During stimulation, they were able to modulate the activity of previously paralyzed muscles voluntarily in order to produce three to five-fold increases in their step elevation or adjust their stride length to increasing treadmill belt speeds.

The development of next-generation spinal cord neuromodulation therapies required a series of technological advances, both in preclinical models and for clinical applications. These innovations included novel spinal implants, real-time control infrastructures, upgraded firmware for pulse generators, personalized computational models and spatiotemporal stimulation algorithms (Wenger et al. 2016; Minev et al. 2015; Capogrosso et al. 2013;
Capogrosso et al. 2018; Moraud et al. 2016; Wenger et al. 2014; Capogrosso et al. 2016; Courtine and Bloch 2015). Functional neurosurgeons played a critical role in these early developments. They will continue contributing to designing and optimizing next-generation neurotechnologies that will be uniquely tailored to the requirements of motor-related applications.

\section{Intense training enabled by spinal cord neuromodulation therapies}

Experiments conducted in the 1980s showed that cats with complete SCI could regain independent stepping when they were trained intensively on a treadmill with manual assistance (de Leon et al. 1998). They also regained the ability to stand for several minutes to hours when they were trained for this task (De Leon et al. 1998). However, they then lost the ability to step. These unexpected results showed that the spinal cord could learn a task that was performed regularly, and that taskspecific training altered the anatomical and functional connectivity of the trained spinal circuitry (Tillakaratne et al. 2002; Ichiyama et al. 2011). These results compelled many specialized rehabilitation centers to develop procedures to train paralyzed patients to step on a treadmill with manual assistance-yet, with disappointing outcomes (Dietz et al. 1994). In humans, the excitability of the spinal cord appeared too depressed after SCI to enable the coordinated recruitment of motor neuron 


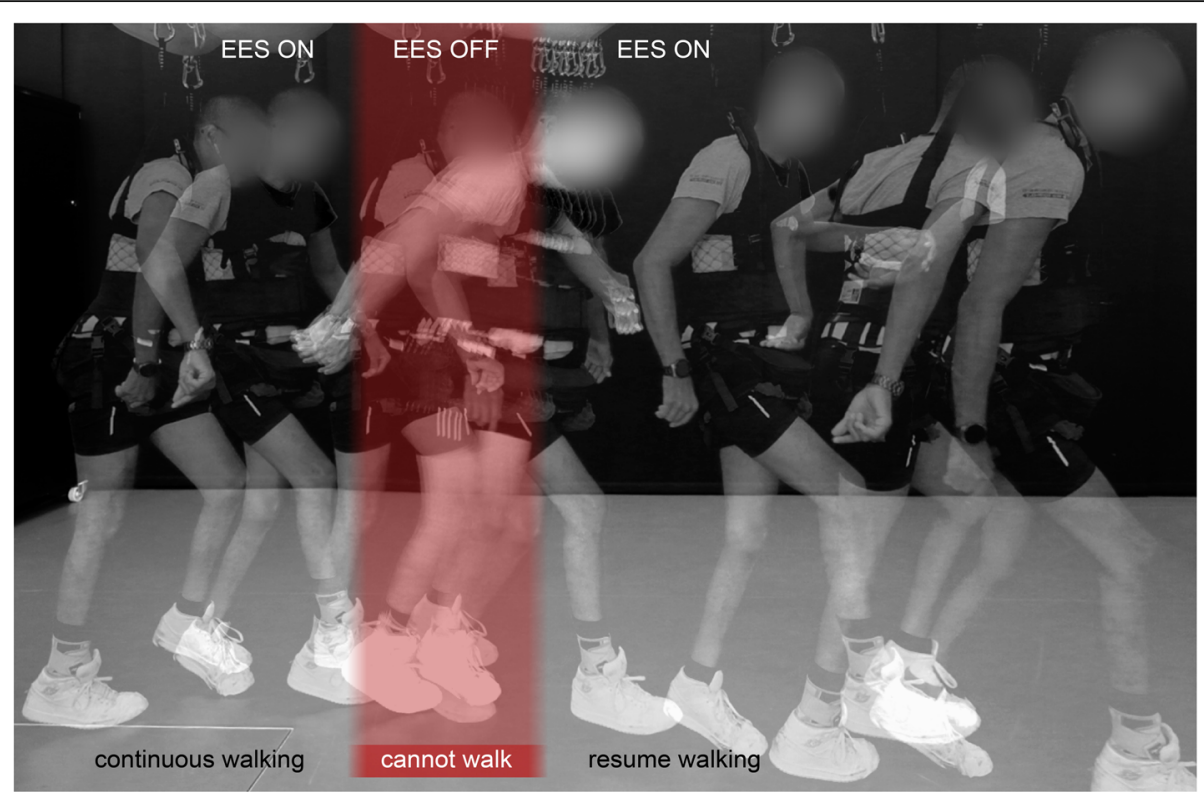

Fig. 4 Chronophotography illustrating the recovery of locomotion during targeted EES. The patient is receiving targeted EES while suspended in a cutting-edge body-weight support system. EES is switched on and off, showing that the recovery of overground locomotion only occurs during EES

pools during passive leg movements (Harkema 2001). Consequently, activity-dependent plasticity was as limited as the amount of activity elicited within the sensorimotor circuitry (Field-Fote 2015).

This understanding suggested that it was critical to enable robust levels of activity during rehabilitative training to steer activity-dependent plasticity in the trained circuitry (Edgerton et al. 2008). During the same period, pharmacological and electrical neuromodulation of the spinal cord had shown the ability to enable stepping in rat models of SCI (Courtine et al. 2009; Ichiyama et al. 2008). The next logical step was to facilitate step training with these neuromodulation therapies. Intense rehabilitative training enabled by neuromodulation therapies induced dramatic improvements of motor capacities. Rats with severe SCI leading to permanent leg paralysis regained the ability to transform environmental cues into specialized motor commands that allowed them to walk overground, climb up a staircase and even swim (van den Brand et al. 2012; Asboth et al. 2018). The systematic dissection of the anatomical and functional mechanisms revealed that the motor cortex orchestrated the recovery, regardless of the specific descending tracts that were spared. In all the studied injury models, it was found that the motor cortex developed new routes involving neuronal relays in the brainstem and/or within bridges of intact tissues in the spinal cord (van den Brand et al. 2012; Asboth et al. 2018). These indirect neuronal pathways were sufficient to transfer taskspecific motor cortex commands past the injury to the executive centers located in the spinal cord that produce leg movements. Importantly, this anatomical and functional reorganization did not take place when rats were trained to step automatically on a treadmill (van den Brand et al. 2012). Critical to trigger the plasticity of descending pathways was a cutting-edge multidirectional robotic body weight support system that positioned the rats bipedally (Dominici et al. 2012). This posture forced them to send motor commands to their leg muscles to propel their body forward toward a food reward. Under these training conditions, rats regained supraspinal control over previously paralyzed muscles even without the need of neuromodulation (Asboth et al. 2018). This neurological recovery highlighted the importance of goal-directed training to promote activity-dependent plasticity throughout the locomotor circuitry.

Clinical studies confirmed these results in humans with SCI. The first clinical studies were conducted using continuous (tonic) EES. Two patients with motor complete SCI but partially preserved sensory function followed intense locomotor training for more than 1 year. Both recovered the ability to walk overground with assistive devices during continuous EES (Angeli et al. 2018). However, they did not show improvement in neurological function. The two other patients in this trial exhibited a functionally complete SCI. Both patients achieved some independent stepping on the treadmill with bodyweight support and manual assistance (Angeli et al. 2018). In a second independent study, one patient with complete paraplegia could step overground with a 
front wheel walker and assistance from therapists (Gill et al. 2018).

The most recent study sought to reproduce the therapeutic conditions that mediated the more pronounced functional recovery in preclinical models of SCI, as described above. This involved the conception of a multidirectional robotic body weight support system that allows patients to walk naturally in a large workspace. A gravity-assist algorithm personalized the amount of forces applied to the trunk in order to establish natural interactions between gravitational forces and gait dynamics while providing the optimal body weight support to the patient (Mignardot et al. 2017). Three patients followed an intensive gait training program enabled by this gravity-assist and spatiotemporal neuromodulation of the lumbosacral spinal cord (Wagner et al. 2018). All three patients could not ambulate or were completely paralyzed prior to their enrollment, despite their involvement in extensive rehabilitation programs. After less than a month of training, all participants were able to walk overground during stimulation. Locomotor performance improved dramatically over the course of the 5 months of training. During stimulation, they regained the ability to walk long distances in ecological settings using assistive devices (Fig. 5). For this purpose, they wore inertial measurement units (IMU) attached to their feet. Decoding algorithms processed these signals to detect foot movements and thus adjust spatiotemporal stimulation sequences to the current needs of the patients (Capogrosso et al. 2018). A watch responding uniquely to their own voice allowed them to switch the stimulation on and off. While this treatment paradigm remains at the stage of a proof of concept, it is worth noting that ecological principles guided its conceptual and technological design. Such ecoprosthetic designs should be encouraged more systematically for the development of neurotechnologies (Courtine and Bloch 2015).

More unexpectedly, all the participants regained voluntary control over the activity of previously paralyzed muscles without stimulation. This neurological recovery enabled the two less affected participants to walk overground with assistive devices in the absence of stimulation. One of the participants could even take a succession of independent steps between parallel bars. These results suggested that spatiotemporal neuromodulation protocols are not only important to promote a robust facilitation of locomotion, but may also play a critical role in steering activity-dependent plasticity in response to training. These protocols aim to increase the excitability of the motor neuron pools that are concomitantly modulated by task-specific sensory information and residual supraspinal command. This spatiotemporal convergence may trigger the reinforcement and growth of synaptic terminals from residual descending projections, as demonstrated in animal models (van den Brand et al. 2012; Asboth et al. 2018). This type of bidirectional spiketiming-dependent plasticity (Holtmaat and Svoboda 2009; Nishimura et al. 2013) has been observed consistently in humans with SCI (Perez et al. 2003; Urbin et al. 2017). Moreover, the repeated activation of proprioceptive afferents with EES may play an important role in promoting anatomical reorganization. Indeed, studies in mice demonstrated that proprioceptive afferents steer the reorganization of descending pathways that promotes a partial recovery of functions after SCI (Takeoka et al. 2014).

These combined studies have provided important proof of concept data on the ability of spinal cord neuromodulation therapies to raise the ceiling of recovery potential for patients with chronic SCI. However, this therapeutic strategy will likely be even more efficacious early after SCI, when the sudden damage has enhanced the potential for anatomical and functional reorganization and the neuromuscular system has not yet undergone the dramatic deterioration that follows chronic paralysis (Dietz 2010). Intervening in the early phase after $\mathrm{SCI}$ will require functional neurosurgeons to liaise effectively with neurologists, physical therapists, and engineers who can often operate in silos. It is important to point out that the recovery of supraspinal control over leg movements is directly correlated with the amount of spared tissues. More severe injuries would require the establishment of a digital bridge to control stimulation protocols, as summarized below.

\section{Brain-computer interface technologies}

The original work from Evarts on the encoding of movement in the motor cortex (Evarts 1967) and from Fetz on the ability to train animals to control the activity of single neurons (Fetz 1969) paved the way towards brain computer interfaces (BCI). Accordingly, BCIs decode motor or cognitive intentions from neural recordings and translate these predictions into commands for computer programs or robotic arms (Gilja et al. 2015; Jarosiewicz et al. 2015). Implantable BCI technologies consist of intracortical microelectrode arrays (Utah arrays) that allow the recording of spiking activity, or electrode arrays positioned epidurally or subdurally over the cerebral cortex to monitor electrocorticogram signals (ECoG). Intracortical probes provide a high degree of spatial resolution (single neurons), but the signals tend to extinguish rapidly. Cortical grids allow more stable recordings but their spatial resolution may be insufficient for the most sophisticated prosthetic applications (Borton et al. 2013). The neural interfaces that have been used clinically are connected to a transdermal connector, which is not always well tolerated by patients and prone to infections. A survey of paralyzed patients demonstrated that they were twice as likely to adopt wireless technology compared to wired equivalents and that there were concerns around the aesthetic awkwardness of current BCI 


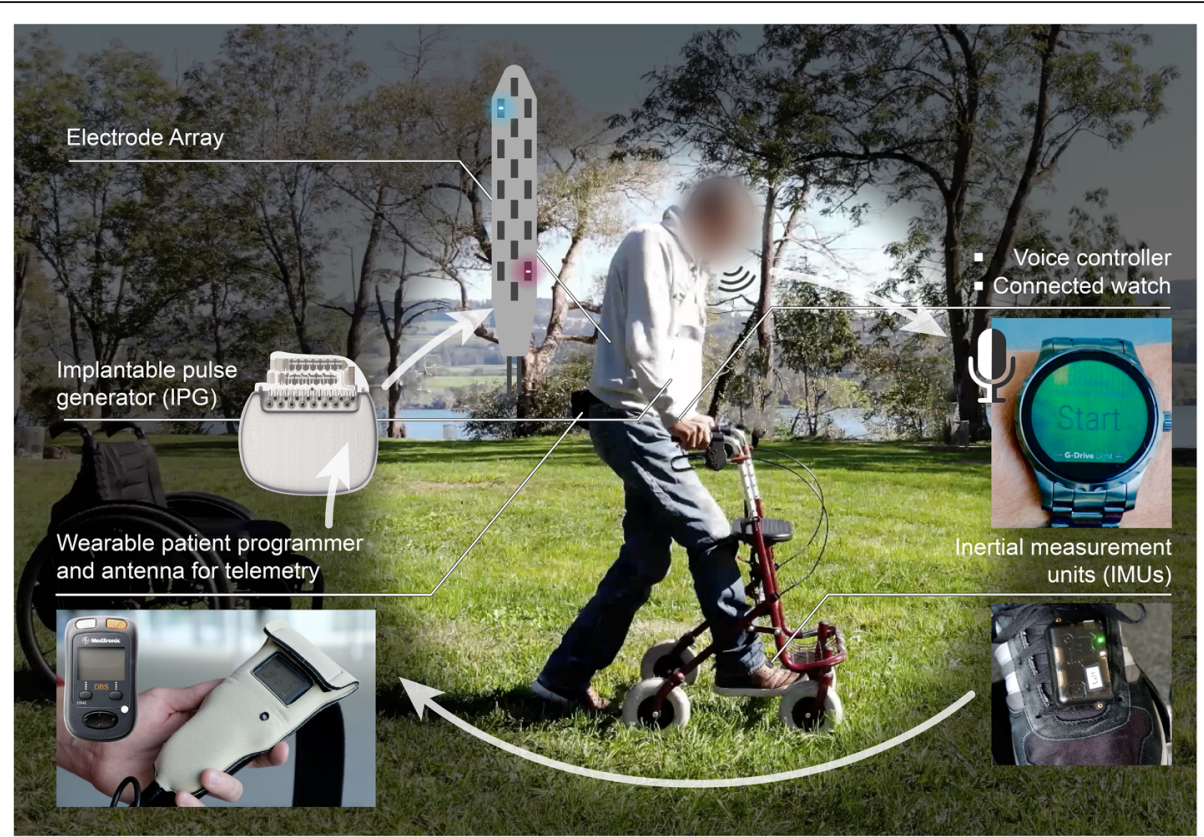

Fig. 5 Ecological principles should guide the development of bioelectronic technology for SCl. Making the technology useable in the patient's natural setting is paramount to its utility. This photograph illustrates the technological framework that enables real-time control of EES outside the laboratory environment. Developing technology based on these ecological principles will require the input and collaborative effort of multiple specialties including neurosurgeons, neurologists, rehabilitation specialists, physiotherapists, engineers, and scientists in order to make bioelectronic technology for patients with $\mathrm{SCl}$ safe and user-friendly

designs in addition to the chances of infection (Blabe et al. 2015). Various academic institutions and companies are developing wireless recording technologies that have already been validated in animal models (Yin et al. 2014; Mestais et al. 2015).

The most advanced BCI demonstrators have reached impressive levels of performance. Individuals with severe SCI have been able to operate biomimetic robotic arms (Hochberg et al. 2012; Collinger et al. 2013) to execute complex manual tasks using neural signals recorded from the primary motor cortex (M1). Moreover, encoding of touch pressure information into somatosensory cortex stimulation restored the ability to distinguish pressure-like sensations in each finger of the robotic hand (Flesher et al. 2016). Two individuals even learned to map M1 activity to neuromuscular stimulation programs in order to mobilize the upper limbs (Bouton et al. 2016; Ajiboye et al. 2017). The first patient used an array of 130 electrodes nested in a flexible sleeve wrapped around the arm. After 15 months of training, the patient was able to perform manual tasks requiring him to open his hand, perform a cylindrical palmar grasp and a precision pinch grasp (Bouton et al. 2016). In the second patient, 36 percutaneous electrodes were implanted into 18 muscles innervating the shoulder, elbow and hand. The patient was able to generate cortical commands to mobilize his arm in order to reach and drink from a mug and to feed himself (Ajiboye et al. 2017). Both studies provided important proof-of-concept data but also highlighted pragmatic issues that may preclude the rapid clinical dissemination of these BCIs. One of the key limitations was the difficulty to coordinate the direct recruitment of so many muscles in order to stabilize the posture of the arm and realize the tasks with fluidity.

$\mathrm{BCI}$ technologies have also been developed to restore leg movements (Fig. 1). Gait events such as the onset of the swing phase can be reliably decoded from M1 activity (Capogrosso et al. 2016; Bonizzato et al. 2018). These detections can trigger EES protocols that facilitate locomotor movements of the legs. Moreover, the cumulative firing of cortical ensemble populations can be linked to the intensity of the stimulation in order to determine the amplitude of leg movements. Rats with an SCI leading to leg paralysis were thus able to use this proportional brain-spine interface (BSI) to walk overground and accommodate leg movements to climb up a staircase (Bonizzato et al. 2018). This concept has successfully been translated into a BSI that restored locomotion in a non-human primate model of transient paralysis (Capogrosso et al. 2016). Intracortical microelectrode arrays were implanted in the leg area of M1. A wireless link mapped neural decoding of swing and stance events to EES protocols that promoted leg movements associated with these events. As early as 6 days postlesion and without any prior training, this BSI restored weight-bearing locomotion of a paralyzed leg. In addition to the immediate recovery of leg movements, mounting 
evidence suggested that brain-actuated prostheses may augment training-mediated reorganization of nerve fibers (Bonizzato et al. 2018; Biasiucci et al. 2018; Donati et al. 2016). Rehabilitation programs closing the loop between circuits located above and below the injury may increase use-dependent neuroplasticity of residual connections through bidirectional spike-timing-dependent neuroplasticity (Ethier et al. 2015; Krucoff et al. 2016; McPherson et al. 2015). The neurological recovery observed in humans with SCI when rehabilitation is supported by spatiotemporal EES protocols may obey the same principles (see above) (Wagner et al. 2018). However, this interpretation remains speculative. More work is necessary to dissect the underlying mechanisms, and thus justify the surgical implantation of brain-spine interfaces in human patients. The computational complexity and skilled technological support may also need to be factored in prior to envisioning the clinical deployment of these neuroprostheses.

Electrode technologies are advancing rapidly, which may remedy some of the limitations of current probes. For example, the development of high-density silicone probes called Neuropixels has allowed the recording of approximately 100 neurons in freely moving mice (Stringer et al. 2019; Juavinett et al. 2018). The insertion of multiple Neuropixel probes enabled the simultaneous recording of thousands of neurons covering the visual and sensorimotor cortex, hippocampal formation, striatum, thalamus, and midbrain in mice (Stringer et al. 2019). This new technology has the potential to expand the number of brain regions that can be monitored in humans. Probe stiffness has been shown to damage to brain tissue and increase inflammation, which reduces signal stability and quality (Lacour et al. 2016). A new "sewing machine" system may remedy this issue: a single fine, stiff needle is used to insert many fine and flexible polymer electrodes into the brain (Hanson et al. 2019). This method ensures a maximal stiffness when penetrating brain tissue while maximizing flexibility and minimizing the size of the implant once inside the brain in order to reduce inflammation. Similarly, the soft implant termed electronic dura matter or e-dura can be inserted for extensive periods of time below the dura matter without causing significant inflammation (Minev et al. 2015). In rats, e-dura was surgically implanted over the motor cortex to monitor locomotor-related cortical activity, and over the spinal cord to deliver electrical and pharmacological stimulation that restored walking after paralysis. Improvements in electrode technologies are opening new avenues for improved recording and stimulation of the brain and spinal cord for patients with SCI.

\section{Modulation of the spinal cord to regulate autonomic functions}

EES has also demonstrated widespread benefits to autonomic systems including bowel and bladder function
(Herrity et al. 2018; Walter et al. 2018) as well as the more extensively studied improvements in cardiovascular function (Aslan et al. 2018; Darrow et al. 2019; Harkema et al. 2018a; Harkema et al. 2018b; West et al. 2018) (Fig. 1). In the first case study, EES mediated immediate improvements in the blood pressure response to an orthostatic challenge and ameliorated the blood flow in the brain (West et al. 2018). The immediate ability of EES to stabilize blood pressure during an orthostatic challenge was then replicated (Darrow et al. 2019; Harkema et al. 2018a; Altaf et al. 2017). Moreover, the repeated application of EES protocols optimized for the modulation of blood pressure led to long-term improvements in cardiovascular regulation (Harkema et al. 2018b). These clinical observations are important, since improvements of cardiovascular functions are among the top health priorities for individuals with SCI (Anderson 2004) and a leading cause of death for this population (Garshick et al. 2005).

These results in patients with chronic SCI also raise the intriguing possibility to deliver EES during the subacute phase after injury. The maintenance of blood pressure during the first few days and weeks that follow an $\mathrm{SCI}$ is of particular clinical importance due to its significant volatility during this period. It is specifically this volatility that has spawned surgical teams to develop methods to optimize hemodynamic stabilization. The maintenance of spinal cord perfusion pressure contributes to predicting neurological recovery (Saadoun et al. n.d.; Squair et al. 2017). Currently, blood pressure is managed with noradrenergic and dopaminergic agonists, but these pharmacological agents are known to induce adverse events in the acute phase after injury (Altaf et al. 2017). Moreover, these slow-acting pharmacological agents cannot mitigate the bouts of severe hypo-perfusion that commonly occur in patients in the acute phase of SCI despite rigorous management of blood pressure (Kong et al. 2013). Bioelectronic implants may thus complement the arsenal of methods that are available to manage hemodynamics in the acute and sub-acute phase after an SCI and limit secondary complications such as autonomic dysreflexia.

The immediate increase in blood pressure in response to EES indicates that the activation of the sympathetic circuitry is driving the control of blood pressure. What remains unclear, however, is the mechanism by which EES delivered to the lumbar enlargement can modulate the sympathetic circuitry located within the thoracic spinal cord. It is therefore imperative to dissect the circuits through which EES modulate blood pressure. This knowledge is essential to operate a transition from empirical methods to evidence-based EES strategies that are optimized for blood pressure regulation. For example, the computational and physiological procedures that led to the development of spatiotemporal EES 
protocols (Wenger et al. 2016; Wenger et al. 2014; Formento et al. 2018) could be replicated to identify the optimal sites of stimulation and biologically-compliant EES protocols targeting the autonomic circuitry. The resulting conceptual and technological framework would not only lead to more effective treatments but would also guide neurosurgeons in the placement of the lead and configuration of stimulation protocols. Effectiveness and ease-of-use considerations are both pivotal for the widespread dissemination of bioelectronic treatments.

\section{Targeting circuits above the SCI: supralesional neuromodulation therapies \\ Engaging hindbrain circuits involved in producing locomotion}

Deep brain stimulation (DBS) of basal ganglia nuclei is a well-established treatment for movement disorders such as Parkinson's disease, essential tremor, and inherited dystonias (Lozano and Lipsman 2013). DBS has also been used to modulate circuits above the SCI, but only in preclinical models. Studies conducted in rodent models have demonstrated that DBS delivered within the mesencephalic locomotor region (MLR) could improve locomotion SCI (Fig. 2). Historical studies conducted in Russia in the 1960s showed that electrical stimulation of this region engages reticulospinal neurons to trigger locomotion with a pace that is proportional to the stimulation amplitude (Ryczko and Dubuc 2013). Due to their distributed topology in the spinal cord, a fraction of reticulospinal fibers often survive the $\mathrm{SCI}$, although they remain functionally silent when the lesion is severe (Asboth et al. 2018). The delivery of continuous electrical stimulation in the vicinity of the MLR immediately triggered walking in rats with such severe SCI (Bachmann et al. 2013). Increasing the intensity of stimulation resulted in greater walking speed and high step frequency. The stimulation also increased the range of leg motion and reduced the amount of paw dragging. The MLR is functionally equivalent to the pedunculopontine nucleus (PPN) region in humans. DBS delivered in the PPN in humans with Parkinson's disease has reduced freezing of gait and falls, albeit results have been variable (Stefani et al. 2007; Tsang et al. 2010). A phase one clinical trial has been approved in the Spinal Cord Injury Center Balgrist to test this approach in five patients with partial SCI (https://clinicaltrials.gov/ct2/show/NCT03053791).

The nucleus raphe magnus (NRM) has also been targeted with electrical stimulation in rodent models of SCI in order to augment the release of serotonin. Indeed, this region is the main source of serotonin to the spinal cord (Jordan et al. 2008). In one study, $5 \mathrm{~min}$ of $8 \mathrm{~Hz}$ stimulation alternated with $5 \mathrm{~min}$ of rest for $12 \mathrm{~h}$ during the day with $12 \mathrm{~h}$ of nocturnal rest was applied chronically after a mid-thoracic contusion SCI (Hentall and Burns 2009). NRM stimulation was found to reverse forepaw allodynia at 6 weeks after injury. However, there was no difference between the stimulated and non-stimulated groups in terms of lesion cavity size, volume of contusion, and on neuronal preservation although there was reduced astroglial scar formation (Hentall and Burns 2009).

Compared to the extensive literature on the impact of $\mathrm{SCI}$ on spinal circuits and descending projections within the spinal cord, there is a paucity of studies that investigated SCI-related changes in brain circuit dynamics, and how specific circuits contribute to steering recovery after SCI. However, there is an increasing understanding that the brain is critically needed to cure SCI (Sawada et al. 2015; Isa 2017). As researchers continue dissecting circuit properties following spinal cord damage, novel targets might be discovered to improve functional recovery with neuromodulation therapies delivered within supraspinal structures.

\section{Augmenting circuit reorganization with vagal nerve stimulation}

Another area of neuromodulation that has received attention is vagal nerve stimulation (VNS) (Fig. 2). Previous research has demonstrated that the precise temporal pairing of vagal nerve stimulation with movement execution can improve motor recovery in rodent models of stroke (Hulsey et al. 2016; Khodaparast et al. 2014; Khodaparast et al. 2016). VNS is thought to lead to the release of monoamines within the cerebral cortex, which may promote plasticity of neural circuits and enhance motor learning (Hulsey et al. 2016). Based on these encouraging results, this strategy was tested in rodent models of unilateral cervical contusion (C6) (Ganzer et al. 2018). Rats were trained to retrieve food reward with their forepaw. Each successful grasp was followed by an electrical burst delivered to the VNS via a bipolar cuff electrode implanted around the left cervical vagus nerve. VNS resulted in significantly improved reaching force compared to rehabilitation alone. The temporal contingence between VNS and the executed movement was critical to promote the recovery. Anatomical and electrophysiological experiments showed that this rehabilitation paradigm enhanced the reorganization of cortical circuits and promoted the growth of new corticospinal tract projections within the cervical spinal cord (Ganzer et al. 2018). Due to its broad functional connectome, the vagal nerve augments the activity of various sensorimotor and autonomic systems. Therefore, VNS likely increases the level of activity within the circuits that are also contributing to movement execution-thus engaging activity-dependent plasticity rules (Edgerton and Gad 2018).

\section{Augmenting circuit reorganization with cortical surface stimulation}

Activity leads to the functional and anatomical reinforcement of the repeatedly activated neural connections 
(Edgerton et al. 2004; Raineteau and Schwab 2001; Cote et al. 2017; Torres-Espin et al. 2018). These well-known physiological principles fostered the development of stimulation paradigms that aim to enhance the activity of neurons with residual neural projections in the spinal cord after SCI. The goal was to promote the growth of new connections in order to improve functional recovery. For instance, electrical motor cortex stimulation has been shown to mediate robust sprouting of spared corticospinal tract fibers. This anatomical reorganization has been associated with improvement of skilled locomotion in rodent models of SCI (Carmel and Martin 2014; Zareen et al. 2017). In this scenario, the stimulation was applied continuously for many hours per day. However, previous studies using spinal cord or vagal nerve stimulation showed that pairing the stimulation with movement execution during rehabilitation may further augment the impact of this treatment (Ganzer et al. 2018).

Similar principles have been applied in humans with SCI using noninvasive technologies. For example, transcranial magnetic stimulation (TMS) applied over the human motor cortex augmented the transmission along descending neural pathways. This increase in conductivity improved motor functions and reduced spasticity (Tazoe and Perez 2015; Long et al. 2017). Along the same vein, paired associative stimulation of the motor cortex and reflex circuits located below the SCI durably augmented the efficacy of the recruited circuits (Mishra et al. 2017; Dixon et al. 2016). These approaches may increase recovery after partial SCI that spare corticospinal tract projections. Neurotechnologies for chronic electrical motor cortex stimulation are available for clinical use in humans. We thus anticipate that clinical trials may test the efficacy of these bioelectronic treatment paradigms to augment functional recovery in humans with SCI.

\section{New role for functional neurosurgery in $\mathrm{SCl}$ medicine}

The role of the functional neurosurgeon in SCI medicine is currently restricted to the occasional treatment of spasticity or chronic pain in the chronic stage of SCI. Acute treatments are usually performed by spine surgeons. The advent of bioelectronic technologies will transform the role of functional neurosurgeons in spinal pathology (Borton et al. 2013). The flurry of advances in SCI-related bioelectronic medicine is opening unprecedented opportunities to impact the neurological recovery and quality of life of patients with SCI. Obviously, functional neurosurgeons will be in charge of the precise implantation of stimulating and recording neural interfaces over the spinal cord or within the brain; together with active electronics. The pre-operative identification of the optimal implant location and intraoperative guidance for inserting and securing implants will require interactions with neural engineers and healthcare professionals who will also follow the patients post-operatively. Indeed, critical to SCI-related bioelectronic treatments is the need for extensive tuning of the therapies post-operatively during long-lasting and highly personalized rehabilitation programs. This specificity may require more sustained involvement by functional neurosurgeons in the deployment of the treatments. They will have to maintain constant interactions with interventional neurologists who will intervene in the neurological recovery of their patients. These interventional neurologists will dialogue with the functional neurosurgeons and rehabilitation teams to identify the optimal treatment options based on the current neurological status, functional needs, and recovery potential of each patient at each relevant time-point, asking questions such as: Is hemodynamic stabilization critical at this time point? Is there potential for increasing neurological recovery with neurotechnologies that enable active motor rehabilitation? Can we anticipate increased anatomical reorganization of neuronal connections with chronic modulation of the brain regions containing neurons with spared projections in the spinal cord? Is there a potential benefit to provide a $\mathrm{BCI}$ treatment to enable the control of computers or robotic arms with brain signals, and thus to improve interactions with the environment? Many questions and opportunities will thus open a new dialogue in neurorestorative interventional medicine and neuroprosthetics. Finally, we anticipate that this bioelectronic medicine revolution will not be limited to SCI, but will quickly expand to other fields such as traumatic brain injury, stroke, and neurodegenerative disorders.

\section{Conclusions}

SCI remains a challenging disease to treat. Despite having significant impacts on lives of patients across the world, years of research into improving neurologic outcomes after injury have yet to find a cure. Relatively recently, there has been a surge in bioelectronic technological developments including spatiotemporal epidural spinal stimulators, brain-spine interfaces, and deep brain stimulation paradigms for various locomotor diseases including SCI. With these developments, there have been clinical improvements in human SCI patients never seen before. The potential promise of these new technologies for SCI has significant implications for clinicians treating SCI patients, especially neurosurgeons. Traditionally, spinal surgeons have been at the forefront of generating guidelines for spinal trauma. However, the increasing involvement of functional neurosurgery in treating SCI will likely parallel the development of new technologies for improving function after SCI. As bioelectronic technologies continue to advance, close collaboration and dialogue between 
multiple professions including surgeons, neurologists, and engineers will be a necessity more than ever before.

\section{Abbreviations}

BCl: Brain-computer interface; BSI: Brain-spine interface; CSF: Cerebrospinal fluid; DBS: Deep brain stimulation; ECoG: Electrocorticogram; EES: Epidural electrical stimulation; FEM: Finite element modelling; IMU: Inertial measurement units; M1: Primary motor cortex; MLR: Mesencephalic locomotor region; MRI: Magnetic resonance imaging; NRM: Nucleus raphe magnus; PPN: Pedunculopontine nucleus; SCl: Spinal cord injury; TMS: Transcranial magnetic stimulation; VNS: Vagal nerve stimulation

\section{Acknowledgements}

Jean-Baptiste Mignardot for all the illustrations.

\section{Authors' contributions}

NC, JWS, JB, and GC conceived the review and were major contributors to the writing of the manuscript. All authors read and approved the final manuscript.

\section{Funding}

This work was supported in part by Canadian Institutes of Health Research (CIHR) Fellowships (NC and JWS) and a European Research Council (ERC) grant, which aided in providing salary for the authors.

\section{Availability of data and materials}

Not applicable.

\section{Ethics approval and consent to participate}

The figures were elaborated from data obtained in the clinical trial STIMO, which has been approved by the ethics authorities of Switzerland (SwissMedic 2016-MD-0002), and received the consent of patients to participate.

\section{Consent for publication}

Participants provide their consent to publish the photographs in the figures of the paper.

\section{Competing interests}

JB and GC hold various patents in bioelectronics and are founders and shareholders of GTX medical, a company developing bioelectronic implants in direct relationships with the reviewed work.

\section{Author details}

${ }^{1}$ École polytechnique fédérale de Lausanne (EPFL), Campus Biotech, Center for Neuroprosthetics and Brain Mind Institute, 1202 Genève, Switzerland. 2Department of Neurosurgery, University of Toronto, Toronto, Ontario, Canada. ${ }^{3}$ Cumming School of Medicine, University of Calgary, Calgary, Canada. ${ }^{4} \mathrm{MD} / \mathrm{PhD}$ Training Program, University of British Columbia, Vancouver, Canada. ${ }^{5}$ Department of Neurosurgery, University Hospital of Lausanne (CHUV), Lausanne, Switzerland. 'Defitech Center for Interventional Neurotherapies, EPFL / CHUV, Lausanne, Switzerland.

\section{Received: 30 March 2019 Accepted: 13 June 2019}

\section{Published online: 11 July 2019}

\section{References}

Ajiboye AB, Willett FR, Young DR, Memberg WD, Murphy BA, Miller JP, Walter BL, Sweet JA, Hoyen HA, Keith MW, et al. Restoration of reaching and grasping movements through brain-controlled muscle stimulation in a person with tetraplegia: a proof-of-concept demonstration. Lancet. 2017;389(10081):1821-30.

Altaf F, Griesdale DE, Belanger L, Ritchie L, Markez J, Ailon T, Boyd MC, Paquette S, Fisher CG, Street J, et al. The differential effects of norepinephrine and dopamine on cerebrospinal fluid pressure and spinal cord perfusion pressure after acute human spinal cord injury. Spinal Cord. 2017;55(1):33-8.

Anderson KD. Targeting recovery: priorities of the spinal cord-injured population. J Neurotrauma. 2004;21(10):1371-83.

Angeli C, Edgerton VR, Gerasimenko Y, Harkema S. Reply: no dawn yet of a new age in spinal cord rehabilitation. Brain. 2015;138(Pt 7):e363.
Angeli CA, Boakye M, Morton RA, Vogt J, Benton K, Chen Y, Ferreira CK, Harkema SJ. Recovery of over-ground walking after chronic motor complete spinal cord injury. N Engl J Med. 2018;379(13):1244-50.

Angeli CA, Edgerton VR, Gerasimenko YP, Harkema SJ. Altering spinal cord excitability enables voluntary movements after chronic complete paralysis in humans. Brain. 2014;137(Pt 5:1394-409.

Arber S, Costa RM. Connecting neuronal circuits for movement. Science. 2018;360(6396):1403-4.

Asboth L, Friedli L, Beauparlant J, Martinez-Gonzalez C, Anil S, Rey E, Baud L, Pidpruzhnykova G, Anderson MA, Shkorbatova P, et al. Cortico-reticulospinal circuit reorganization enables functional recovery after severe spinal cord contusion. Nat Neurosci. 2018;21(4):576-88.

Aslan SC, Legg Ditterline BE, Park MC, Angeli CA, Rejc E, Chen Y, Ovechkin AV, Krassioukov A, Harkema SJ. Epidural spinal cord stimulation of lumbosacral networks modulates arterial blood pressure in individuals with spinal cord injury-induced cardiovascular deficits. Front Physiol. 2018;9:565.

Bachmann LC, Matis A, Lindau NT, Felder P, Gullo M, Schwab ME. Deep brain stimulation of the midbrain locomotor region improves paretic hindlimb function after spinal cord injury in rats. Sci Transl Med. 2013;5(208):208ra146.

Biasiucci A, Leeb R, Iturrate I, Perdikis S, Al-Khodairy A, Corbet T, Schnider A, Schmidlin $\mathrm{T}$, Zhang $\mathrm{H}$, Bassolino $\mathrm{M}$, et al. Brain-actuated functional electrical stimulation elicits lasting arm motor recovery after stroke. Nat Commun. 2018;9(1):2421.

Blabe CH, Gilja V, Chestek CA, Shenoy KV, Anderson KD, Henderson JM. Assessment of brain-machine interfaces from the perspective of people with paralysis. J Neural Eng. 2015;12(4):043002.

Bonizzato M, Pidpruzhnykova G, DiGiovanna J, Shkorbatova P, Pavlova N, Micera S, Courtine G. Brain-controlled modulation of spinal circuits improves recovery from spinal cord injury. Nat Commun. 2018;9(1):3015.

Borton D, Micera S, Millan Jdel R, Courtine G. Personalized neuroprosthetics. Sci Transl Med. 2013;5(210):210rv212.

Bouton CE, Shaikhouni A, Annetta NV, Bockbrader MA, Friedenberg DA, Nielson DM, Sharma G, Sederberg PB, Glenn BC, Mysiw WJ, et al. Restoring cortical control of functional movement in a human with quadriplegia. Nature. 2016:533(7602):247-50.

Capogrosso M, Milekovic T, Borton D, Wagner F, Moraud EM, Mignardot J-B, Buse N, Gandar J, Barraud Q, Xing D, et al. A brain-spine interface alleviating gait deficits after spinal cord injury in primates. Nature. 2016;539(7628):284-8.

Capogrosso M, Wagner FB, Gandar J, Moraud EM, Wenger N, Milekovic T, Shkorbatova P, Pavlova N, Musienko P, Bezard E, et al. Configuration of electrical spinal cord stimulation through real-time processing of gait kinematics. Nat Protoc. 2018;13(9):2031-61.

Capogrosso M, Wenger N, Raspopovic S, Musienko P, Beauparlant J, Bassi Luciani L, Courtine G, Micera S. A computational model for epidural electrical stimulation of spinal sensorimotor circuits. J Neurosci. 2013;33(49):19326-40.

Carmel JB, Martin JH. Motor cortex electrical stimulation augments sprouting of the corticospinal tract and promotes recovery of motor function. Front Integr Neurosci. 2014:8:51.

Collinger JL, Wodlinger B, Downey JE, Wang W, Tyler-Kabara EC, Weber DJ, McMorland AJ, Velliste M, Boninger ML, Schwartz AB. High-performance neuroprosthetic control by an individual with tetraplegia. Lancet. 2013;381(9866):557-64.

Cote MP, Murray M, Lemay MA. Rehabilitation strategies after spinal cord injury: inquiry into the mechanisms of success and failure. J Neurotrauma. 2017;34(10):1841-57.

Courtine G, Bloch J. Defining ecological strategies in neuroprosthetics. Neuron. 2015:86(1):29-33.

Courtine G, Gerasimenko $Y$, van den Brand $\mathrm{R}$, Yew A, Musienko $\mathrm{P}$, Zhong $\mathrm{H}$, Song B, Ao Y, Ichiyama RM, Lavrov I, et al. Transformation of nonfunctional spinal circuits into functional states after the loss of brain input. Nat Neurosci. 2009:12(10):1333-42.

Danner SM, Hofstoetter US, Freund B, Binder H, Mayr W, Rattay F, Minassian K. Human spinal locomotor control is based on flexibly organized burst generators. Brain. 2015;138(Pt 3):577-88.

Darrow D, Balser D, Netoff TI, Krassioukov A, Phillips A, Parr A, et al. Epidural Spinal Cord Stimulation Facilitates Immediate Restoration of Dormant Motor and Autonomic Supraspinal Pathways after Chronic Neurologically Complete Spinal Cord Injury. J Neurotrauma [Internet]. 2019. Available from: https:// www.liebertpub.com/doi/10.1089/neu.2018.6006

de Leon RD, Hodgson JA, Roy RR, Edgerton VR. Locomotor capacity attributable to step training versus spontaneous recovery after spinalization in adult cats. J Neurophysiol. 1998;79(3):1329-40. 
De Leon RD, Hodgson JA, Roy RR, Edgerton VR. Full weight-bearing hindlimb standing following stand training in the adult spinal cat. J Neurophysiol. 1998;80(1):83-91.

Dietz V. Behavior of spinal neurons deprived of supraspinal input. Nat Rev Neurol. 2010;6(3):167-74

Dietz V, Colombo G, Jensen L. Locomotor activity in spinal man. Lancet. 1994;344(8932):1260-3.

Dixon L, Ibrahim MM, Santora D, Knikou M. Paired associative transspinal and transcortical stimulation produces plasticity in human cortical and spinal neuronal circuits. J Neurophysiol. 2016;116(2):904-16.

Dominici N, Keller U, Vallery H, Friedli L, van den Brand R, Starkey ML, Musienko P, Riener R, Courtine $G$. Versatile robotic interface to evaluate, enable and train locomotion and balance after neuromotor disorders. Nat Med. 2012;18(7):1142-7.

Donati AR, Shokur S, Morya E, Campos DS, Moioli RC, Gitti CM, Augusto PB, Tripodi S, Pires CG, Pereira GA, et al. Long-term training with a brain-machine Interface-based gait protocol induces partial neurological recovery in paraplegic patients. Sci Rep. 2016;6:30383.

Dy C, Dyhre-Poulsen P, Courtine G, Gerasimenko Y, Harkema S. Modulation of multisegmental monosynaptic responses during walking in spinal cord-injured humans. Program No. 515.11. Washington, DC: Society for Neuroscience; 2005

Edgerton VR, Courtine G, Gerasimenko YP, Lavrov I, Ichiyama RM, Fong AJ, Cai LL, Otoshi CK, Tillakaratne NJ, Burdick JW, et al. Training locomotor networks. Brain Res Rev. 2008;57(1):241-54.

Edgerton VR, Gad P. Is the vagus nerve our neural connectome? eLife [Internet] 2018;7. Available from: https://elifesciences.org/articles/35592

Edgerton VR, Tillakaratne NJ, Bigbee AJ, de Leon RD, Roy RR. Plasticity of the spinal neural circuitry after injury. Annu Rev Neurosci. 2004;27:145-67.

Ethier C, Gallego JA, Miller LE. Brain-controlled neuromuscular stimulation to drive neural plasticity and functional recovery. Curr Opin Neurobiol. 2015:33:95-102.

Evarts EV. Representation of movements and muscles by pyramidal tract neurons of the precentral motor cortex. In: Yahr MD, Purpura DP editors. Neurophysiological basis of Normal and abnormal motor activities. New York: Raven Press; 1967. p. 215-53.

Fehlings MG, Tetreault LA, Wilson JR, Kwon BK, Burns AS, Martin AR, Hawryluk G, Harrop JS. A clinical practice guideline for the Management of Acute

Spinal Cord Injury: introduction, rationale, and scope. Global Spine J. 2017;7(3 Suppl):84S-94S

Fetz EE. Operant conditioning of cortical unit activity. Science. 1969;163(3870):955-8.

Field-Fote EC. Exciting recovery: augmenting practice with stimulation to optimize outcomes after spinal cord injury. Prog Brain Res. 2015;218:103-26.

Flesher SN, Collinger JL, Foldes ST, Weiss JM, Downey JE, Tyler-Kabara EC, Bensmaia SJ, Schwartz AB, Boninger ML, Gaunt RA. Intracortical microstimulation of human somatosensory cortex. Sci Transl Med. 2016; 8(361):361ra141.

Fong AJ, Roy RR, Ichiyama RM, Lavrov I, Courtine G, Gerasimenko Y, Tai YC, Burdick J, Edgerton VR. Recovery of control of posture and locomotion after a spinal cord injury: solutions staring us in the face. Prog Brain Res. 2009;175:393-418.

Formento E, Minassian K, Wagner F, Mignardot JB, Le Goff-Mignardot CG, Rowald A, Bloch J, Micera S, Capogrosso M, Courtine G. Electrical spinal cord stimulation must preserve proprioception to enable locomotion in humans with spinal cord injury. Nat Neurosci. 2018;21(12):1728-41.

Ganzer PD, Darrow MJ, Meyers EC, Solorzano BR, Ruiz AD, Robertson NM, et al. Closed-loop neuromodulation restores network connectivity and motor control after spinal cord injury. eLife [Internet]. 2018;7. Available from: https:// elifesciences.org/articles/32058

Garshick E, Kelley A, Cohen SA, Garrison A, Tun CG, Gagnon D, Brown R. A prospective assessment of mortality in chronic spinal cord injury. Spinal cord 2005;43(7):408-16.

Gerasimenko Y, Lu D, Modaber M, Zdunowski S, Gad P, Sayenko D, Morikawa E, Haakana P, Ferguson AR, Roy RR, et al. Noninvasive reactivation of motor descending control after paralysis. J Neurotrauma. 2015;32(24):1968-80.

Gerasimenko YP, Ichiyama RM, Lavrov IA, Courtine G, Cai L, Zhong H, Roy RR, Edgerton VR. Epidural spinal cord stimulation plus quipazine administration enable stepping in complete spinal adult rats. J Neurophysiol. 2007;98(5):2525-36.
Gilja V, Pandarinath C, Blabe CH, Nuyujukian P, Simeral JD, Sarma AA, Sorice BL, Perge JA, Jarosiewicz B, Hochberg LR, et al. Clinical translation of a high-performance neural prosthesis. Nat Med. 2015; 21(10):1142-5.

Gill ML, Grahn PJ, Calvert JS, Linde MB, Lavrov IA, Strommen JA, Beck LA, Sayenko DG, Van Straaten MG, Drubach DI, et al. Neuromodulation of lumbosacral spinal networks enables independent stepping after complete paraplegia. Nat Med 2018;24(11):1677-82.

Grahn PJ, Lavrov IA, Sayenko DG, Van Straaten MG, Gill ML, Strommen JA, Calvert JS, Drubach DI, Beck LA, Linde MB, et al. Enabling task-specific volitional motor functions via spinal cord neuromodulation in a human with paraplegia. Mayo Clin Proc. 2017;92(4):544-54.

Hanson TL, Diaz-Botia CA, Kharazia V, Maharbiz MM, Sabes PN. The "sewing machine" for minimally invasive neural recording. bioRxiv [Internet]. 2019. Available from: http://biorxiv.org/lookup/doi/10.1101/578542

Harkema SJ. Neural plasticity after human spinal cord injury: application of locomotor training to the rehabilitation of walking. Neuroscientist. 2001;7(5):455-68.

Harkema SJ, Legg Ditterline B, Wang S, Aslan S, Angeli CA, Ovechkin A, Hirsch GA. Epidural spinal cord stimulation training and sustained recovery of cardiovascular function in individuals with chronic cervical spinal cord injury. JAMA Neurol. 2018b;75(12):1569-71.

Harkema SJ, Wang S, Angeli CA, Chen Y, Boakye M, Ugiliweneza B, Hirsch GA. Normalization of blood pressure with spinal cord epidural stimulation after severe spinal cord injury. Front Hum Neurosci. 2018a;12:83.

Hentall ID, Burns SB. Restorative effects of stimulating medullary raphe after spinal cord injury. J Rehabil Res Dev. 2009;46(1):109-22.

Herman R, He J, D'Luzansky S, Willis W, Dilli S. Spinal cord stimulation facilitates functional walking in a chronic, incomplete spinal cord injured. Spinal Cord. 2002:40(2):65-8.

Herrity AN, Williams CS, Angeli CA, Harkema SJ, Hubscher CH. Lumbosacral spinal cord epidural stimulation improves voiding function after human spinal cord injury. Sci Rep. 2018;8(1):8688.

Hochberg LR, Bacher D, Jarosiewicz B, Masse NY, Simeral JD, Vogel J, Haddadin S, Liu J, Cash SS, van der Smagt P, et al. Reach and grasp by people with tetraplegia using a neurally controlled robotic arm. Nature. 2012;485(7398):372-5

Holinski BJ, Mazurek KA, Everaert DG, Toossi A, Lucas-Osma AM, Troyk P, EtienneCummings R, Stein RB, Mushahwar VK. Intraspinal microstimulation produces over-ground walking in anesthetized cats. J Neural Eng. 2016;13(5):056016.

Holtmaat A, Svoboda K. Experience-dependent structural synaptic plasticity in the mammalian brain. Nat Rev Neurosci. 2009;10(9):647-58.

Hulsey DR, Hays SA, Khodaparast N, Ruiz A, Das P, Rennaker RL, Kilgard MP. Reorganization of motor cortex by Vagus nerve stimulation requires cholinergic innervation. Brain Stimul. 2016;9(2):174-81.

Ichiyama RM, Broman J, Roy RR, Zhong H, Edgerton VR, Havton LA. Locomotor training maintains normal inhibitory influence on both alpha- and gammamotoneurons after neonatal spinal cord transection. J Neurosci. 2011;31(1):26-33.

Ichiyama RM, Courtine G, Gerasimenko YP, Yang GJ, van den Brand R, Lavrov IA, Zhong $H$, Roy RR, Edgerton VR. Step training reinforces specific spinal locomotor circuitry in adult spinal rats. J Neurosci. 2008;28(29):7370-5.

Isa T. The brain is needed to cure spinal cord injury. Trends Neurosci. 2017;40(10):625-36

Jarosiewicz B, Sarma AA, Bacher D, Masse NY, Simeral JD, Sorice B, Oakley EM, Blabe C, Pandarinath C, Gilja V, et al. Virtual typing by people with tetraplegia using a self-calibrating intracortical brain-computer interface. Sci Transl Med. 2015;7(313):313ra179.

Jordan LM, Liu J, Hedlund PB, Akay T, Pearson KG. Descending command systems for the initiation of locomotion in mammals. Brain Res Rev. 2008;57(1):183-91.

Juavinett AL, Bekheet G, Churchland AK. Chronically-implanted Neuropixels probes enable high yield recordings in freely moving mice. bioRxiv [Internet]. 2018. Available from: http://biorxiv.org/lookup/doi/10.1101/406074

Kasten MR, Sunshine MD, Secrist ES, Horner PJ, Moritz CT. Therapeutic intraspinal microstimulation improves forelimb function after cervical contusion injury. J Neural Eng. 2013;10(4):044001.

Khodaparast N, Hays SA, Sloan AM, Fayyaz T, Hulsey DR, Rennaker RL, Kilgard MP. Vagus nerve stimulation delivered during motor rehabilitation improves recovery in a rat model of stroke. Neurorehabil Neural Repair. 2014;28(7): 698-706.

Khodaparast N, Kilgard MP, Casavant R, Ruiz A, Qureshi I, Ganzer PD, Rennaker RL, Hays SA. Vagus nerve stimulation during rehabilitative training improves 
forelimb recovery after chronic ischemic stroke in rats. Neurorehabil Neural Repair. 2016;30(7):676-84

Kong CY, Hosseini AM, Belanger LM, Ronco JJ, Paquette SJ, Boyd MC, Dea N, Street J, Fisher CG, Dvorak MF, et al. A prospective evaluation of hemodynamic management in acute spinal cord injury patients. Spinal cord. 2013:51(6):466-71.

Krucoff MO, Rahimpour S, Slutzky MW, Edgerton VR, Turner DA. Enhancing nervous system recovery through Neurobiologics, neural Interface training, and neurorehabilitation. Front Neurosci. 2016;10:584

Lacour SP, Courtine G, Guck J. Materials and technologies for soft implantable neuroprostheses. Nat Rev Mater. 2016;1:16063.

Lavrov I, Courtine G, Dy CJ, van den Brand R, Fong AJ, Gerasimenko Y, Zhong H, Roy RR, Edgerton VR. Facilitation of stepping with epidural stimulation in spinal rats: role of sensory input. J Neurosci. 2008a;28(31):7774-80.

Lavrov I, Dy CJ, Fong AJ, Gerasimenko Y, Courtine G, Zhong H, Roy RR, Edgerton VR. Epidural stimulation induced modulation of spinal locomotor networks in adult spinal rats. J Neurosci. 2008b;28(23):6022-9.

Long J, Federico P, Perez MA. A novel cortical target to enhance hand motor output in humans with spinal cord injury. Brain. 2017;140(6):1619-32.

Lozano AM, Lipsman N. Probing and regulating dysfunctional circuits using deep brain stimulation. Neuron. 2013;77(3):406-24.

Lu DC, Edgerton VR, Modaber M, AuYong N, Morikawa E, Zdunowski S, Sarino ME, Sarrafzadeh M, Nuwer MR, Roy RR, et al. Engaging cervical spinal cord networks to Reenable volitional control of hand function in tetraplegic patients. Neurorehabil Neural Repair. 2016;30(10):951-62.

McPherson JG, Miller RR, Perlmutter SI. Targeted, activity-dependent spinal stimulation produces long-lasting motor recovery in chronic cervical spinal cord injury. Proc Natl Acad Sci U S A. 2015;112(39):12193-8.

Mestais CS, Charvet G, Sauter-Starace F, Foerster M, Ratel D, Benabid AL. WIMAGINE: wireless 64-channel ECoG recording implant for long term clinical applications. IEEE Trans Neural Syst Rehabil Eng. 2015;23(1):10-21.

Mignardot J-B, Le Goff CG, van den Brand R, Capogrosso M, Fumeaux N, Vallery $\mathrm{H}$, et al. A multidirectional gravity-assist algorithm that enhances locomotor control in patients with stroke or spinal cord injury. Sci Transl Med. 2017; 9(399):eaah3621.

Minev IR, Musienko P, Hirsch A, Barraud Q, Wenger N, Moraud EM, Gandar J, Capogrosso M, Milekovic T, Asboth L, et al. Biomaterials. Electronic dura mater for long-term multimodal neural interfaces. Science. 2015;347(6218):159-63.

Mishra AM, Pal A, Gupta D, Carmel JB. Paired motor cortex and cervical epidural electrical stimulation timed to converge in the spinal cord promotes lasting increases in motor responses. J Physiol. 2017;595(22):6953-68.

Moraud EM, Capogrosso M, Formento E, Wenger N, DiGiovanna J, Courtine G, Micera S. Mechanisms underlying the neuromodulation of spinal circuits for correcting gait and balance deficits after spinal cord injury. Neuron. 2016;89(4):814-28.

Musienko P, Courtine G, Tibbs JE, Kilimnik V, Savochin A, Garfinkel A, Roy RR, Edgerton VR, Gerasimenko Y. Somatosensory control of balance during locomotion in decerebrated cat. J Neurophysiol. 2012;107(8):2072-82.

Musienko P, van den Brand R, Marzendorfer O, Roy RR, Gerasimenko Y, Edgerton VR, Courtine G. Controlling specific locomotor behaviors through multidimensional monoaminergic modulation of spinal circuitries. J Neurosci. 2011;31(25):9264-78.

Nishimura Y, Perlmutter SI, Eaton RW, Fetz EE. Spike-timing-dependent plasticity in primate corticospinal connections induced during free behavior. Neuron. 2013:80(5):1301-9.

Perez MA, Field-Fote EC, Floeter MK. Patterned sensory stimulation induces plasticity in reciprocal ia inhibition in humans. J Neurosci. 2003;23(6):2014-8.

Raineteau O, Schwab ME. Plasticity of motor systems after incomplete spinal cord injury. Nat Rev Neurosci. 2001;2(4):263-73.

Rattay F, Minassian K, Dimitrijevic MR. Epidural electrical stimulation of posterior structures of the human lumbosacral cord: 2. Quantitative analysis by computer modeling. Spinal Cord. 2000;38(8):473-89.

Rossignol S, Giroux N, Chau C, Marcoux J, Brustein E, Reader TA. Pharmacological aids to locomotor training after spinal injury in the cat. J Physiol. 2001:533(Pt 1:65-74.

Ryczko D, Dubuc R. The multifunctional mesencephalic locomotor region. Curr Pharm Des. 2013;19(24):4448-70.

Saadoun S, Chen S, Papadopoulos MC. Intraspinal pressure and spinal cord perfusion pressure predict neurological outcome after traumatic spinal cord injury. J Neurol Neurosurg Psychiatry. 2017;88(5):452-3.
Sawada M, Kato K, Kunieda T, Mikuni N, Miyamoto S, Onoe H, Isa T, Nishimura Y. Function of the nucleus accumbens in motor control during recovery after spinal cord injury. Science (New York, N Y ). 2015;350(6256):98-101.

Squair JW, Bélanger LM, Tsang A, Ritchie L, Mac-Thiong J-M, Parent S, Christie S, Bailey C, Dhall S, Street J, et al. Spinal cord perfusion pressure predicts neurologic recovery in acute spinal cord injury. Neurology. 2017;89(16):1660-7.

Stefani A, Lozano AM, Peppe A, Stanzione P, Galati S, Tropepi D, Pierantozzi M, Brusa L, Scarnati E, Mazzone P. Bilateral deep brain stimulation of the pedunculopontine and subthalamic nuclei in severe Parkinson's disease. Brain. 2007;130(Pt 6):1596-607.

Stringer C, Pachitariu M, Steinmetz N, Reddy CB, Carandini M, Harris KD. Spontaneous behaviors drive multidimensional, brainwide activity. Science. 2019;364(6437):255.

Takeoka A, Vollenweider I, Courtine G, Arber S. Muscle spindle feedback directs locomotor recovery and circuit reorganization after spinal cord injury. Cell. 2014;159(7):1626-39.

Tazoe T, Perez MA. Effects of repetitive transcranial magnetic stimulation on recovery of function after spinal cord injury. Arch Phys Med Rehabil. 2015;96(4 Suppl):S145-55.

Tillakaratne NJ, de Leon RD, Hoang TX, Roy RR, Edgerton VR, Tobin AJ. Use-dependent modulation of inhibitory capacity in the feline lumbar spinal cord. J Neurosci. 2002;22(8):3130-43.

Torres-Espin A, Beaudry E, Fenrich K, Fouad K. Rehabilitative training in animal models of spinal cord injury. J Neurotrauma. 2018;35(16):1970-85.

Tsang EW, Hamani C, Moro E, Mazzella F, Poon YY, Lozano AM, Chen R. Involvement of the human pedunculopontine nucleus region in voluntary movements. Neurology. 2010;75(11):950-9.

Urbin MA, Ozdemir RA, Tazoe T, Perez MA. Spike-timing-dependent plasticity in lower-limb motoneurons after human spinal cord injury. J Neurophysiol. 2017;118(4):2171-80.

van den Brand R, Heutschi J, Barraud Q, DiGiovanna J, Bartholdi K, Huerlimann M, Friedli L, Vollenweider I, Moraud EM, Duis S, et al. Restoring voluntary control of locomotion after paralyzing spinal cord injury. Science. 2012;336(6085):1182-5.

Wagner FB, Mignardot JB, Le Goff-Mignardot CG, Demesmaeker R, Komi S, Capogrosso M, Rowald A, Seanez I, Caban M, Pirondini E, et al. Targeted neurotechnology restores walking in humans with spinal cord injury. Nature. 2018;563(7729):65-71.

Walter M, Lee AHX, Kavanagh A, Phillips AA, Krassioukov AV. Epidural spinal cord stimulation acutely modulates lower urinary tract and bowel function following spinal cord injury: a case report. Front Physiol. 2018;9:1816.

Wenger N, Moraud EM, Gandar J, Musienko P, Capogrosso M, Baud L, Le Goff CG, Barraud Q, Pavlova N, Dominici N, et al. Spatiotemporal neuromodulation therapies engaging muscle synergies improve motor control after spinal cord injury. Nat Med. 2016;22(2):138-45.

Wenger N, Moraud EM, Raspopovic S, Bonizzato M, DiGiovanna J, Musienko P, Morari M, Micera S, Courtine G. Closed-loop neuromodulation of spinal sensorimotor circuits controls refined locomotion after complete spinal cord injury. Sci Transl Med. 2014;6(255):255ra133.

West CR, Phillips AA, Squair JW, Williams AM, Walter M, Lam T, Krassioukov AV. Association of Epidural Stimulation with Cardiovascular Function in an individual with spinal cord injury. JAMA Neurol. 2018;75(5):630-2.

Yin M, Borton DA, Komar J, Agha N, Lu Y, Li H, Laurens J, Lang Y, Li Q, Bull C, et al. Wireless Neurosensor for full-Spectrum electrophysiology recordings during free behavior. Neuron. 2014;84(6):1170-82.

Zareen N, Shinozaki M, Ryan D, Alexander H, Amer A, Truong DQ, Khadka N, Sarkar A, Naeem S, Bikson M, et al. Motor cortex and spinal cord neuromodulation promote corticospinal tract axonal outgrowth and motor recovery after cervical contusion spinal cord injury. Exp Neurol. 2017;297:179-89.

Zimmermann JB, Seki K, Jackson A. Reanimating the arm and hand with intraspinal microstimulation. J Neural Eng. 2011;8(5):054001.

\section{Publisher's Note}

Springer Nature remains neutral with regard to jurisdictional claims in published maps and institutional affiliations. 